\title{
SOCIAL NETWORKING WEBSITES: NEW EDUCATIONAL SPACE
}

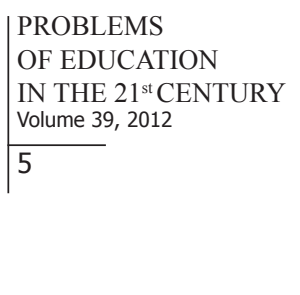

\author{
Vincentas Lamanauskas \\ University of Šiauliai, Lithuania \\ E-mail: v.lamanauskas@ef.su.It
}

Over the latter decade the spread of information communication technologies was going on in various directions. Technological possibilities grew up very significantly (Lamanauskas, 2011). Especially rapid was the development of the internet and technologies related with it. A lot of internet service providers occurred in the market, their number still continues to grow. The internet link methods change - from the ordinary usage of phone line modems (dial - up) to broadband internet technology (DSL) and cable TV internet nets. It can be asserted, that over the mentioned period Web 1.0 internet (static, used for getting information) was changed by Web 2.0 internet (social). The internet diaries, social portals, technologies allowing live communication on the internet (Internet Relay Chat, IRC), talk programme Windows Live Messenger (MSN), ICQ forums and other have occurred and are spreading. With the occurrence of "Skype", internet telephony acquired a qualitatively new characteristic and practically became a daily routine. Thus, today a consumer can create his profile on the internet, can make friends, communicate in the interest groups and so on. It can be stated, that every human being in his own way contributes to the internet and at the same time to ICT development, in general. It is obvious, that together with technological problems arise social internet problems as well. Social networking websites (SNW) are closely related with economical, psychological, educational, valeological and other aspects. There is a lack of researches based on socio-educational social networking website aspects. It is important to know not only how much time the consumers spend surfing the net, but how much time is allotted for communicating in social networking websites, which of them are the most popular and why, how the respondents evaluate social networking website functions, what in general they know about them, what advantages, disadvantages and threats they discern. Finally, it is important to find out whether usage of social networking websites makes information - communication abilities better in any way.

It is obvious, that usage of social networking websites is constantly growing. In Lithuania, a rapid growth of usage has been observed in recent years, taking into account local (national) social networking websites as well. Facebook.com is one among 10 mostly visited networks in Lithuania. Lithuanian consumers are not an exception - not a small part of them also use several social networking websites. Both in the world and in Lithuania, business takes an active interest in social networking websites. An evident tendency is the expansion of SNW possibilities in business environment. If earlier it was thought that usage of SNW is a waste of time, in the latter years business finds more and more reasons why social networking websites ought to be used. This is marketing, service and product advertisement, new client search, cooperation development and so on. The other thing - the amount and the flow of information will certainly not decrease and therefore information usage and management in general, will remain urgent.

The other tendency is also rather distinct. Social networking websites "move" into educational space as well. However, a great number of problems exist here. Nowadays teachers (speaking especially about Lithuanian situation) are not properly prepared in ICT field. Though ICT usage competences are being improved in general, however considerable gaps remain, the shortage of understanding is felt on how to apply information technologies, what their abilities are to make teaching/learning process easier, more effective and interesting for children. ICT in 
PROBLEMS

OF EDUCATION

IN THE $21^{\text {st }}$ CENTURY

Volume 39, 2012

its own way changes rapidly, it is complicated to adjust to existing technological environment.

On the other hand, nowadays children have grown up in ICT surroundings, in the environment more or less filled with technologies. This makes them more susceptible to technologies in general. Thus, teachers' society can't stay behind from ICT development either. Teachers themselves have to be ready for unpredictable future (or at least hardly predictable) and to convey this attitude to children. A continuous demand to improve becomes the cornerstone for every member of society.

The problem of motivation to learn and improve remains urgent. Despite education science achievements, motivation encouragement problem remains one of the most serious ones. However, watching children and teenagers' activities using ICT, especially social networking websites, a very high motivation, a demand to use SNW are fixated. Thus, it is important to use up that motivation in educational sense, in other words, to use up social networking websites abilities in educational sense. It is already a common and understandable thing in itself to speak about higher technologies in industry, medicine, pharmacy, agriculture and so on. Somehow it is spoken very little or not spoken at all about higher technologies in education (pedagogy of higher technology).

Nowadays a lot of various social networking websites (or technologies devoted to creation of social networks online and their effective usage) are used not only for entertainment, leisure or communication, but for teaching/learning purposes. E.g., in business field enterprises and organisations, there is a well known internal learning and informing system, using which one can operatively convey information, news and so on (Intra Organizational Learning, IOL).Very widely are used the systems devoted for raising professional qualification both of teachers and students and in some cases for acquiring education as well (Formal Structured Learning, FSL). Speaking about social networking websites, a very significant becomes so-called accidental/ spontaneous learning. This occurs when a consumer using social networking websites gets or finds out something new very often not realizing consciously it himself (Accidental \& Serendipitous Learning, ASL). It is without doubt, that modern SNW in a certain sense realize accidental learning. Teacher's role continues to be problematic. It remains an open question to what extent technologies can overtake the teacher's roles of being a mediator and a human being; and this is indispensable since such a mediation generates students' cognitive and social processes and is a highly important factor for the whole learning process (Bregant, Aberšek, 2011).

Thus, can social networks carry out effectively educational function? Can they become a proper professional development instrument? We can formulate a lot of questions. The phenomenon of social networking websites is new and complicated, rapidly changing. The term itself "social networking websites" is rather new (2004). Quite often this term carries in itself a negative meaning. Not in vain, speaking about educational value of social networking websites, another term is used - (Educational networking, http://www.educationalnetworking.com/). The fact is that in the global world self-management learning becomes a distinct tendency in the field of cooperative teaching and teaching in general. Social networking websites and their technologies not only form proper conditions for such learning but also directly encourage it. It can be bravely stated, that the first social networking websites wave has already come down. Social networking websites creation, development and usage strategy is being thought in a new way. Educational social networking websites value remains a problematic and open question. 


\section{References}

Bregant, J., Aberšek, B. (2011). Artificial Intelligence versus Human Talents in Learning Process. Problems of Education in the 21st Century (Information \& Communication Technology in Natural Science Education - 2011), 37, 38-47.

Lamanauskas, V. (2011). Digital Education: Some Implications. Journal of Baltic Science Education, 10 (4), 216-218.

Received: January 31, 2012

Accepted: March 01, 2012

Professor, Siauliai University, Natural Science Education Research Centre, 25-119 P.Višinskio Street, LT- 76351, Siauliai, Lithuania.

Phone: +370 68795668 .

E-mail: lamanauskas@projektas.It, v.lamanauskas@ef.su.It

Website: http://www.lamanauskas.projektas.It 